\title{
Management of faecal incontinence in residential aged care
}

John Guinane, Rosie Crone

\section{Background}

Faecal incontinence significantly affects a patient's quality of life, and limited research has been conducted into effective interventions that are specific to residential aged care. Australian and New Zealand prevalence data indicate a general faecal incontinence rate of $12-13 \%$ in older adults and up to $50 \%$ in residential aged care.

\section{Objective}

The objective of this article is to describe the suggested initial investigation and management of faecal incontinence in older adults residing in residential aged care. Discussion of invasive management strategies is outside the scope of this article.

\section{Discussion}

Faecal incontinence is difficult to treat and there is limited evidence to support any treatment beyond three to six months. However, recognition remains the major barrier to treatment with noninvasive interventions that are available to reduce episode frequency and prevent complications. A combination of exercise programs and integrated continence care in residential aged care may provide significant benefit if there are sufficient staffing resources available.
THE INTERNATIONAL CONTINENCE SOCIETY defines faecal incontinence as 'the involuntary loss of liquid or solid stool that is a social or hygienic problem'. ${ }^{1}$ However, a recent review ${ }^{2}$ identified significant heterogeneity in the definitions commonly used in the literature to define and measure significant faecal incontinence. The most common frequency measure was 'leakage of liquid and/or solid stool at least once per month over the past 12 months'. Faecal incontinence can be a marker of increased frailty ${ }^{3}$ and remains persistently underdiagnosed. ${ }^{4}$ Severe faecal incontinence is also an independent predictor of mortality. ${ }^{5}$ Limited Australian and New Zealand prevalence data indicate a general rate of $12-13 \%$ in older adults and up to $50 \%$ in residential aged care (RAC). ${ }^{2}$ North American studies have found a similar prevalence of up to $50 \%$ in RAC. ${ }^{6}$

Despite the significantly higher prevalence of faecal incontinence in RAC, limited research has been conducted into effective interventions that are specific to this environment. The objective of this article is to describe the suggested initial investigation and management of faecal incontinence in older adults residing in RAC. Discussion of invasive management strategies is outside the scope of this article. Invasive management options may not be suitable and are poorly researched in this patient group, who are likely to have coexisting pathologies that lower the odds of a successful outcome. Even in ideal circumstances, invasive interventions have only been moderately successful. ${ }^{7}$

\section{Aetiology of faecal incontinence in older adults in RAC}

Faecal incontinence can occur with alterations to stool consistency or delivery, diminished rectal compliance, altered anorectal sensation or abnormal sphincter function. ${ }^{8}$ Major cognitive and neurological diseases that are common in older age can contribute to faecal incontinence. Dementia can impair mobility and diminish voiding awareness and inhibitory control. ${ }^{9}$ Parkinson's disease slows gut transit time and contributes to constipation risk. ${ }^{10}$ Stroke and other causes of impaired mobility also contribute to constipation risk. Additionally, patients who require significant hands-on mobility assistance may be reluctant to call for help when necessary. ${ }^{11}$ Deficiencies in activities of daily living, such as feeding, dressing and toilet use, have been correlated with increased risk of faecal incontinence.$^{3}$

Constipation is common in older adults and may manifest as overflow incontinence. However, research has inconsistently associated constipation with faecal incontinence ${ }^{12}$ and has failed to associate constipation treatment with reduced faecal incontinence episodes. ${ }^{13}$ Faecal impaction - the presence of hard, immovable stool in the rectum following chronic constipation - may be more definitively linked. In the presence of impaction, faecal incontinence may be caused by an altered anorectal angle, low anal pressures and decreased anorectal sensation. ${ }^{14}$ Faecal impaction has been found in up to $42 \%$ of patients admitted into a geriatric ward. ${ }^{15}$ Lower spinal cord dysfunction has been hypothesised as a cause of faecal impaction in older adults. ${ }^{15}$

There is some limited evidence in the RAC population that men may be at higher risk of faecal incontinence. ${ }^{12}$ The major risk factor for faecal incontinence is age; up to $21.7 \%$ people with this condition are 8 o years or older. ${ }^{16}$ Moving into RAC can increase the risk of faecal incontinence. ${ }^{12}$ In the RAC population, use of patient 
restraints has been identified as a significant risk factor, even when correcting for the reason for restraint application. ${ }^{17}$

\section{Investigation of faecal incontinence in RAC}

Active case finding may be necessary, and primary neurological causes, such as spinal cord injury, should be ruled out. Digital rectal examination (DRE) remains necessary to assess for rectal stool loading, rectal prolapse, deficient anal tone and significant pelvic floor descent. Loss of visible sphincter constriction after stroking the perianal area (anal wink reflex) can result from damage to the $\mathrm{S}_{2}-4$ nerve roots or the pudendal nerve. Inspection and DRE can accurately detect larger external sphincter defects, ${ }^{18}$ and may identify complications, such as perianal dermatitis. ${ }^{9}$ If a primary neurological cause is suspected, lower limb or more extensive neurological examination may be warranted. The patient's medication list should be examined to identify unnecessary medications, including opioids and anticholinergics, that slow gut transit time.

Simple investigations include standard faecal microscopy and culture to assess for infection, and abdominal X-ray to quantify any degree of faecal loading..$^{19}$ Other causes of diarrhoea, aside from infection, should be screened and treated accordingly. More advanced testing normally requires specialist referral, and is reserved for patients who fail basic measures or have a suspected sphincter injury.

\section{Management of faecal incontinence in RAC}

Coexisting mental health conditions may affect treatment success, ${ }^{20}$ and there is limited evidence to support any treatment beyond three to six months. ${ }^{21}$

Dietary recommendations, with increased fluid and fibre, may be useful to improve stool volume and consistency. The optimal daily fluid target is unknown; a fluid intake of less than two litres has not been associated with higher levels of chronic constipation. ${ }^{22}$ One randomised controlled trial (RCT) demonstrated that psyllium supplementation may be more effective than carboxymethlycellulose or gum Arabic. ${ }^{23}$ Psyllium dosed at 16 g per day for 32 days reduced the incidence of faecal incontinence to 2.5 times per week, compared with 5.5 times for placebo. Psyllium is commonly found in oats and other high-fibre cereals. Many commercial preparations are also available.

If decreased rectal compliance is suspected, increasing stool volume may worsen symptoms because of reduced volume perception. Reducing poorly digestible sugars may be useful, as lactose malabsorption was found to rise with age in one small study. ${ }^{24}$ Hydrogen breath tests remain best practice for diagnosing carbohydrate malabsorption. ${ }^{25}$

Pelvic floor muscle retraining has been examined as a potential low-cost therapy with few adverse effects, but outcome variation across the small number of available studies limits the conclusions that can be drawn. ${ }^{21}$ Physiotherapy services are available by referral to a local continence service or to private physiotherapists with specialist qualifications. Liaison between the RAC and continence service may be required to determine funding arrangements.

Anal plugs can be tried, particularly to improve confidence during community access; however, they are poorly tolerated by most people and there is limited large-scale trial evidence for their use. For the minority of patients who are able to tolerate them, anal plugs can be highly successful at controlling faecal incontinence. ${ }^{26}$ However, advice should be sought from continence specialists or continence nurses before recommending the use of anal plugs.

Anal plugs can be obtained from continence product retailers or online distributors for approximately $\$ 5$ per day. This cost is likely to be borne by patients or their families. They are available in two sizes and patients are generally advised to trial the smaller size first. Anal plugs should not be retained for longer than 12 hours and need to be removed prior to defecation.

We recommend referring to the IMPACT ${ }^{19}$ guidelines for Australianspecific best practice management of constipation and faecal impaction in older adults. Overuse of laxatives can contribute to diarrhoea. Abdominal X-ray may be required to verify successful treatment of faecal impaction.

Antidiarrhoeal medications may have a limited role in reducing incontinence from idiopathic chronic diarrhoea; however, there is a significant risk of constipation. There is limited evidence regarding other pharmaceutical options, especially in the older adult population where no specific meta-analysis exists. A Cochrane review of medical treatment for adult faecal incontinence, published in 2013, ${ }^{27}$ found that most of the trials dealt with antidiarrhoeal medications alone. The six studies that tested medications to enhance sphincter function were disappointing and revealed a high rate of complications.

Historically, the RAC sector has lacked the necessary resources to fully implement strategies, such as prompted toileting. Routine assessment of continence in RAC may also be negatively affected by a fear of failing to meet accreditation standards, and a narrow focus on documenting incontinence to receive funding. ${ }^{28}$

Prompted voiding to reduce the frequency of urinary and faecal incontinence was investigated by Ouslander et al in a prospective trial of 165 RAC residents in the US. ${ }^{29}$ The number of continent bowel movements increased, but the number of incontinence episodes did not decrease with the overall number of bowel movements increasing. Exercise programs in RAC have been evaluated in a cost-effectiveness trial. ${ }^{30}$ They improved functional outcomes but did not reduce faecal incontinence frequency.

Exercise combined with integrated continence care has shown more promise. In an RCT of 190 RAC residents in the $\mathrm{US},{ }^{31}$ the treatment group received a brief intervention every two hours, which consisted of prompting toileting and changing as required, in addition to supervised walking or repeated sit-tostands. Fluids were offered before and after each intervention, and additional upper-body resistance training was added to one intervention per day. The intervention resulted in a significant reduction in faecal incontinence episodes; however, the overall number of bowel movements remained low. It was 
estimated that one personal care worker would be required for every five patients in order to provide the intervention on an ongoing basis.

Faecal incontinence remains an independent risk factor for pressure ulcers in frail older adults, ${ }^{32}$ so pressure care should continue to be prioritised in RAC. Perianal dermatitis has been found in $51 \%$ of RAC residents with faecal incontinence, ${ }^{33}$ so preventive barrier treatments should also be implemented. Generally, washable continence garments are not used because repeated cleaning is required. Disposable pads can be useful for containment, but this is likely to increase the risk of dermatitis. Charcoal-based pads can be useful if faecal smearing is the primary problem.

\section{Conclusion}

Faecal incontinence in RAC is highly prevalent, distressing, and difficult to treat, and the evidence base for treatment remains deficient. However, recognition remains the major barrier to treatment, with simple, non-invasive interventions available to reduce faecal incontinence frequency and prevent complications in the RAC environment. Exercise programs combined with integrated continence care have shown the most potential; however, the resource-intensive nature of these interventions may limit their broader deployment unless funding models change.

\section{Key points}

- Faecal incontinence is highly prevalent in older adults living in RAC.

- Faecal incontinence can be a marker of frailty and increased mortality risk.

- Faecal impaction is a common and treatable cause of faecal incontinence in RAC.

- Poor mobility and medications that slow gut transit time, including opioids and anticholinergics, can significantly contribute to the risk of faecal impaction and subsequent faecal incontinence.

- Dietary prescription, with fibre supplementation, may be effective if diminished rectal compliance is not suspected.
- The combination of an exercise program and integrated continence care, consisting of prompted toileting and changing as required, may be the most effective, widely deployable measure.

\section{Authors}

John Guinane MBBS, BMed Sci, Advanced Trainee in Geriatric Medicine, Western Health, Sunshine Hospital, St Albans, Vic. john.guinane@wh.org.au Rosie Crone MBChB, MRCP, FRACP, Clinical Associate Professor and Consultant Geriatrician, Barwon Health, Vic

Competing interests: None.

Provenance and peer review: Not commissioned, externally peer reviewed.

\section{References}

1. Norton C, Whitehead W, Bliss D, Metsola P, Tries J. Conservative and pharmacological management of fecal incontinence in adults. London: The International Continence Society, 2016. Available at www.ics.org/publications/ici_3/v2.pdf/chap24. pdf [Accessed 17 Nov 2017]

2. Guinane J, Crone R. Faecal incontinence in older people in Australia and New Zealand: A narrative review. Aust New Zeal Cont Journal 2017;23(1):6-13.

3. Saga S, Vinsnes A, Mørkved S, Norton C, Seim A. Prevalence and correlates of fecal incontinence among nursing home residents: A population-based cross-sectional study. BMC Geriatr 2013;13(1):87.

4. Ostaszkiewicz J, O'Connell B, Millar L. Incontinence: Managed or mismanaged in hospita settings? Int J Nurs Pract 2008;14(6):495-502.

5. Nakanishi N, Tatara K, Shinsho F, et al. Mortality in relation to urinary and faecal incontinence in elderly people living at home. Age Ageing 1999:28(3):301-06.

6. Chassagne P, Landrin I, Neveu C, et al. Fecal incontinence in the institutionalized elderly: Incidence, risk factors, and prognosis. Am J Med 1999:106(2):185-90.

7. Harari D, Husk J, Lowe D, Wagg A. National audit of continence care: Adherence to National Institute for Health and Clinical Excellence (NICE) Guidance in older versus younger adults with faecal incontinence. Age Ageing 2014;43(6):785-93.

8. Jorge JM, Wexner SD. Etiology and management of fecal incontinence. Dis Colon Rectum 1993;36(1):77-97.

9. Shah BJ, Chokhavatia S, Rose S. Fecal incontinence in the elderly: FAQ. Am J Gastroenterol 2012;107(11):1635-46.

10. Müller-Lissner S. General geriatrics and gastroenterology: Constipation and faecal incontinence. Best Pract Res Clin Gastroenterol 2002;16(1):115-33.

11. Potter J, Norton C, Cottenden C, editors. Bowel care in older people: Research and practice. London: Royal College of Physicians, 2002; p. 132.

12. Johanson JF, Irizarry F, Doughty A. Risk factors for fecal incontinence in a nursing home population. J Clin Gastroenterol 1997;24(3):156-60.

13. Chassagne $P$, Jego $A$, Gloc $P$, et al. Does treatment of constipation improve faecal incontinence in institutionalized elderly patients? Age Ageing 2000;29(2):159-64

14. Read NW, Abouzekry L. Why do patients with faecal impaction have faecal incontinence. Gut 1986;27(3):283-87.

15. Read NW, Abouzekry L, Read MG, Howell P, Ottewell D, Donnelly TC. Anorectal function in elderly patients with fecal impaction. Gastroenterology 1985;89(5):959-66.
16. Campbell AJ, Reinken J, McCosh L. Incontinence in the elderly: Prevalence and prognosis. Age Ageing 1985;14(2):65-70.

17. Nelson RL, Furner SE. Risk factors for the development of fecal and urinary incontinence in Wisconsin nursing home residents. Maturitas 2005;52(1):26-31.

18. Dobben AC, Terra MP, Deutekom M, et al. Anal inspection and digital rectal examination compared to anorectal physiology tests and endoanal ultrasonography in evaluating fecal incontinence. Int J Colorectal Dis 2007;22(7):783-90.

19. Gibson P, Beckwith R, Chiarello P, et al. Impact A guide to the management of constipation and faecal impaction in the older person. Australia; IMPACT, 2010; p. 1-86. Available at www.movicol. com.au/file/IMPACT for Older Patient.pdf [Accessed 31 Oct 2017].

20. Heymen S. Psychological and cognitive variables affecting treatment outcomes for urinary and fecal incontinence. Gastroenterology 2004;126(1 Suppl 1):S146-51.

21. Forte ML, Andrade KE, Butler M, et al. Treatments for fecal incontinence [Internet]. Vol. 165, AHRQ Comparative Effectiveness Reviews. Rockville, US: Agency for Healthcare Research and Quality, 2016.

22. Lindeman RD, Romero LJ, Liang HC, Baumgartner RN, Koehler KM, Garry PJ. Do elderly persons need to be encouraged to drink more fluids? J Gerontol A Biol Sci Med Sci 2000;55(7):M361-65.

23. Bliss DZ, Savik K, Jung HJ, Whitebird R, Lowry A, Sheng $X$. Dietary fiber supplementation for fecal incontinence: A randomized clinical trial. Res Nurs Health 2014;37(5):367-78.

24. Goulding A, Taylor RW, Keil D, Gold E, LewisBarned NJ, Williams SM. Lactose malabsorption and rate of bone loss in older women. Age Ageing 1999;28(2):175-80.

25. Barrett JS, Gibson PR. Fructose and lactose testing. Aust Fam Physician 2012;41(5):293-96.

26. Deutekom M, Dobben AC. Plugs for containing faecal incontinence. Cochrane Database Syst Rev. 2015;(7):CD005086.

27. Omar MI, Alexander CE. Drug treatment for faecal incontinence in adults. Cochrane Database Syst Rev 2013;(6):CD002116.

28. Ostaszkiewicz J, O'Connell B, Dunning T. Fear and overprotection in Australian residential aged-care facilities: The inadvertent impact of regulation on quality continence care. Australas J Ageing 2016;35(2):119-26.

29. Ouslander JG, Simmons S, Schnelle J, Uman G, Fingold S. Effects of prompted voiding on fecal continence among nursing home residents. J Am Geriatr Soc 1996;44(4):424-28.

30. Schnelle JF, Kapur K, Alessi C, et al. Does an exercise and incontinence intervention save healthcare costs in a nursing home population? J Am Geriatr Soc 2003:51(2):161-68.

31. Schnelle JF, Alessi CA, Simmons SF, Al-Samarrai NR, Beck JC, Ouslander JG. Translating clinical research into practice: A randomized controlled trial of exercise and incontinence care with nursing home residents. J Am Geriatr Soc 2002;50(9):1476-83.

32. Baumgarten M, Margolis D, Gruber-Baldini AL, et al. Pressure ulcers and the transition to long-term care. Adv Skin Wound Care 2003;16(6):299-304.

33. Bliss DZ, Zehrer C, Savik K, Smith G, Hedblom E. An economic evaluation of four skin damage prevention regimens in nursing home residents with incontinence: Economics of skin damage prevention. J Wound Ostomy Continence Nurs 2007:34(2):143-52. 